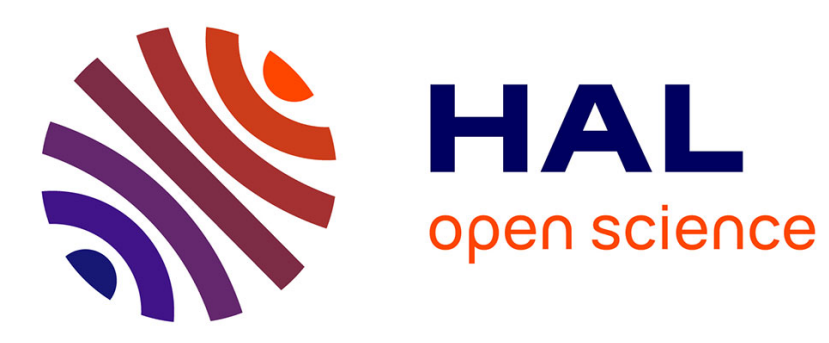

\title{
Macromolecular modifications of poly(etherketoneketone) (PEKK) copolymer at the melting state
}

Tanguy Choupin, Bruno Fayolle, Gilles Regnier, C. Paris, B Brule, J Cinquin

\section{- To cite this version:}

Tanguy Choupin, Bruno Fayolle, Gilles Regnier, C. Paris, B Brule, et al.. Macromolecular modifications of poly(etherketoneketone) (PEKK) copolymer at the melting state. Polymer Degradation and Stability, 2018, 155, pp.103-110. 10.1016/j.polymdegradstab.2018.07.005 . hal-01900956

\section{HAL Id: hal-01900956 https://hal.science/hal-01900956}

Submitted on 22 Oct 2018

HAL is a multi-disciplinary open access archive for the deposit and dissemination of scientific research documents, whether they are published or not. The documents may come from teaching and research institutions in France or abroad, or from public or private research centers.
L'archive ouverte pluridisciplinaire HAL, est destinée au dépôt et à la diffusion de documents scientifiques de niveau recherche, publiés ou non, émanant des établissements d'enseignement et de recherche français ou étrangers, des laboratoires publics ou privés. 


\title{
Macromolecular modifications of poly(etherketoneketone) (PEKK) copolymer at the melting state
}

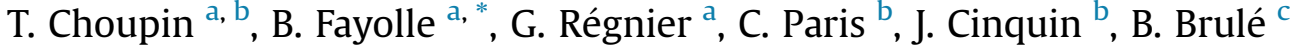 \\ a PIMM, Arts et Metiers ParisTech, CNRS, CNAM, 151 Boulevard de l'Hôpital, 75013, Paris, France \\ b Department of Composites Materials, Airbus Group Innovations, 12 Rue Pasteur, 92150, Suresnes, France

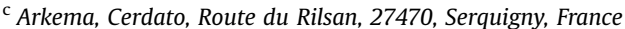

Keywords:

PEKK

Thermal degradation

Crosslinking

Crystallization

PACS:

81.05.Lg

\begin{abstract}
A B S T R A C T
Macromolecular modifications of poly(etherketoneketone) (PEKK) copolymer prepared from diphenyl ether (DPE), terephthalic acid (T) and isophthalic acid (I) with a T/I ratio of 60/40 have been investigated above its melting temperature by gel permeation chromatography (GPC), differential scanning calorimetry (DSC) and rheological measurements to assess the evolution of PEKK matrix during composite consolidation step. We mainly focused in this study on anaerobic conditions, i.e. degradation under nitrogen or in lack of oxygen. During exposure, thermal degradation leads to an increase of weight average molar mass $\mathrm{M}_{\mathrm{w}}$ and viscosity which is typical to crosslinking/branching mechanism as already observed for PEEK in the literature. However, thanks to GPC measurements, it appears that a chain scission mechanism occurs in the same time related to a constant number average molar mass $\mathrm{M}_{\mathrm{n}}$. Crosslinking kinetics are identified at several temperatures between 320 and $400^{\circ} \mathrm{C}$ with rheological measurements from a kinetic scheme governing the crosslinking mechanism. At last, the influence of the crosslinking process on PEKK crystallization is investigated. The final crystallinity and crystallization kinetics decrease with crosslinking due to branching of macromolecular chains.
\end{abstract}

\section{Introduction}

Poly(ether-ketone-ketone) (PEKK) high performance thermoplastics are currently studied with a great interest by the aeronautic industry as matrix for carbon fiber reinforced structural parts. In fact, PEKK composites can be consolidated out of autoclave and they have lower processing temperatures than PEEK composites. The final mechanical performances of composite parts are closely linked to their processing. In fact, depending on the thermal processing cycle, the matrix properties as well as the interaction between the matrix and the carbon fibres are modified. PEKK composites are consolidated at high temperature (around $360^{\circ} \mathrm{C}$ ) to obtain a viscosity decrease of the matrix in order to evacuate all porosities under pressure. During this step, PEKK matrices can evolve due to chemical transformation of the macromolecular chains. This modification could alter the matrices properties and consequently the final mechanical properties of the composite parts $[1,2]$.

\footnotetext{
* Corresponding author. 151 boulevard de l'hôpital, 75013, Paris, France. E-mail address: bruno.fayolle@ensam.eu (B. Fayolle).
}

It has been reported by different authors [3-13] that PEEK undergoes macromolecular modifications and mass losses at high temperature (around $400^{\circ} \mathrm{C}$ ) in both nitrogen and air in an early stage. These macromolecular modifications are attributed to crosslinking mechanisms. This mechanism under nitrogen atmosphere is presented in Fig. 1 [11]. It is initiated by scissions of macromolecular chains located in the carbonyl and ether bonds (Step 1), creating radicals which miss hydrogen molecules (Step 2). Day et al. suggested in a first article [4] that first scissions occurs at the carbonyl functional groups. In a second article [5] as for Tsai et al. [14], they assumed that chain scissions begin at the ether linkages. Other authors $[3,8,14]$ made the assumption that they begin at the same time since activation energies of bond dissociations for ether and carbonyl linkages are very close. Radicals can then rearrange by removing hydrogen molecules from aromatics cycles forming phenyl radicals $\left(\mathrm{P}^{\circ}\right)$ (Step 3 ), which can rearrange with an adjacent radical to produce crosslinks (Step 4). Another possibility for phenyl radical is to rearrange by internal combination, to produce dibenzofuran or fluorenone derivatives:

As a result, the crosslinking increases viscosity of the matrix $[1,9,10]$ which can involve bad impregnation of the carbon fibers 
Initiation

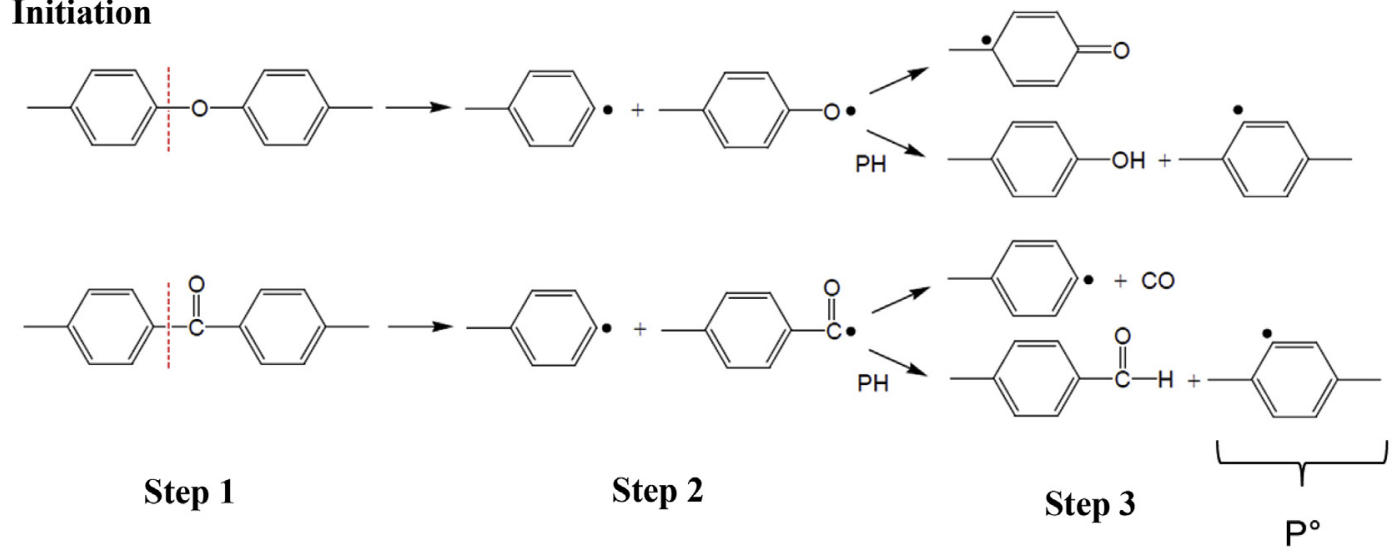

Crosslinking in termination step

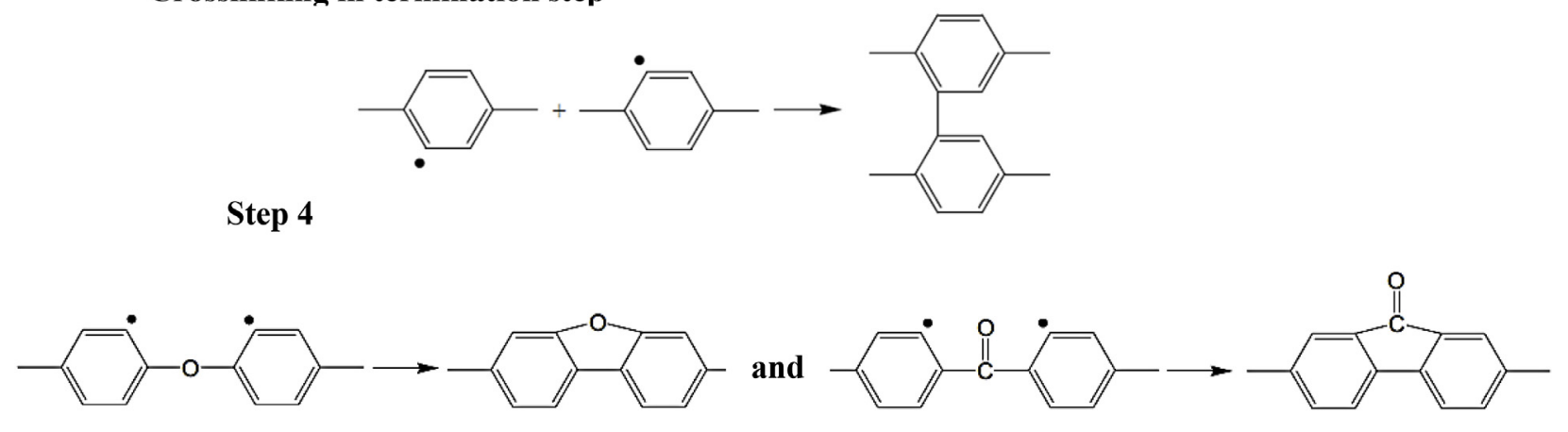

Fig. 1. Crosslinking mechanism steps of PEEK [11].

during processing and thus impact the final health and performance of composite parts. It has also been reported in the literature that after exposure at high temperature, crosslinking decreases the crystallization kinetics and the final crystallinity $[1,2,6,15,16]$ and thus the final mechanical properties of the composite parts [1,2].

The objective of this paper is to assess the macromolecular modifications of PEKK above its melting temperature and identify their origins. We will mainly focus on crosslinking process and assess the kinetic associated to this process as a function of temperature of exposure. A second objective is quantified these macromolecular modifications and model their apparition kinetics.

\section{Experimental}

\subsection{Materials}

PEKK used in this study was provided by Arkema referenced as PEKK 6002. It was prepared from diphenyl ether (DPE), terephthalic acid (T) with para phenyl links and isophthalic acid (I) with meta phenyl links with a T/I ratio of 60/40 (Fig. 2). PEKK 6002 has a weight-and number average molar mass $\left(\mathrm{M}_{\mathrm{w}}\right.$ and $\left.\mathrm{M}_{\mathrm{n}}\right)$ of about 68800 g.mol ${ }^{-1}$ and $29800 \mathrm{~g} \mathrm{~mol}^{-1}$ respectively. PEKK samples were supplied amorphous with no crystalline traces measured by DSC and WAXS. The glass transition and melting temperatures were respectively measured about $155^{\circ} \mathrm{C}$ and $305^{\circ} \mathrm{C}$ by DSC with a heating stage of $10^{\circ} \mathrm{C} / \mathrm{min}$.

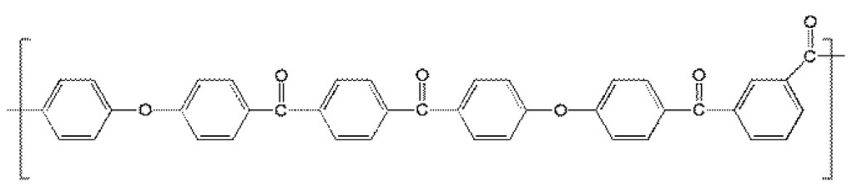

Fig. 2. Chemical structure of PEKK copolymers.

\subsection{Exposure conditions}

Two ways were chosen to perform thermal degradation on PEKK samples. The first one were performed in situ in rheometer or in DSC under nitrogen, see more details in $\S 2.4$ and $\S 2.5$. The second way was used to prepare thermally degraded samples for GPC measurements. For this purpose, thin samples were taken from the core of $2 \mathrm{~mm}$ thick samples exposed at $400^{\circ} \mathrm{C}$ in air. Knowing oxidation is confined at the surface of thick samples due to diffusion limited oxidation, oxidized surface was removed from the core of thick samples. Since oxidation products appear in the oxidized surface layer, it was checked out by FTIR measurements (spectra were not shown here) that no oxidation products were detected in the samples after the oxidized surface layer removal.

\subsection{Gel permeation chromatography (GPC)}

GPC measurements were performed by Arkema Company on a Waters Alliance 2695 device with a Waters 2414 RID detector. Samples preparation and experimental conditions are confidential.

\subsection{Differential scanning calorimetry (DSC)}

Isothermal crystallization analyses were carried out in a TA Instruments Q2000 on PEKK 6002 amorphous granules of about 7-8 $\mathrm{mg}$ previously heated at $400^{\circ} \mathrm{C}$ under nitrogen during $1 \mathrm{~h}, 2 \mathrm{~h}$, $3 \mathrm{~h}$ and $4 \mathrm{~h}$. Specimens were first heated at $10^{\circ} \mathrm{C} \cdot \mathrm{min}^{-1}$ from room temperature to $360^{\circ} \mathrm{C}$ during $5 \mathrm{~min}$. This temperature is above PEKK equilibrium melting temperatures [17] to erase the thermal history and obtain a fully amorphous polymer. Specimens were then cooled at $40^{\circ} \mathrm{C} \cdot \mathrm{min}^{-1}$ to $230^{\circ} \mathrm{C}$ during $240 \mathrm{~min}$ and finally cooled at $40^{\circ} \mathrm{C} \cdot \mathrm{min}^{-1}$ to room temperature. This cooling rate was high enough to make sure that the polymer does not crystallize 
before exposure and the exposure time was long enough to allow the polymer to fully crystallize. Finally, a heat scan at $10^{\circ} \mathrm{C} \cdot \mathrm{min}^{-1}$ to $400^{\circ} \mathrm{C}$ was carried out to measure the glass transition, the melting temperature and the melting enthalpy induced by the crystallization cycle. The glass transition temperature was measured as the inflexion point.

\subsection{Rheological measurements}

Rheological properties of PEKK 6002 were measured with an Anton Paar MCR 502 rheometer under nitrogen for isothermal temperatures conditions. PEKK 6002 amorphous granules previously dried at $120^{\circ} \mathrm{C}$ during $48 \mathrm{~h}$ were first introduced between $25 \mathrm{~mm}$ diameter aluminum parallel plates at the testing temperature and then crushed by the plates separated by a $1 \mathrm{~mm}$ gap. The melted polymer between plates was then deburred. After this step, the polymer was thermally stabilized at the testing temperature before the beginning of the test. This procedure was done as rapidly as possible to neglect the possible modification of the polymer before the analysis. Sinusoidal deformation mode was used with a strain amplitude of $1 \%$ to remain in the viscoelastic linear domain and a frequency of $1 \mathrm{rad} \mathrm{s}^{-1}$ to carry out tests in the Newtonian domain to ensure that the viscosity only depends on the exposure time and temperature.

\section{Results}

\subsection{Gel permeation chromatography (GPC) analysis}

Gel permeation chromatography measurements were carried out on PEKK samples exposed at $400{ }^{\circ} \mathrm{C}$ for duration between 5 and 240 min (see Fig. 3). Less than 5\% of insoluble were measured for all exposure times. It can be noticed a slight appearance of short chains $\left(3000<\mathrm{M}<20000 \mathrm{~g} \mathrm{~mol}^{-1}\right.$ ) after $60 \mathrm{~min}$ of exposure, the major changes witnessed in Fig. 3 is the broadening of the molar mass distribution towards higher molar masses. However, the peak position remains almost constant during the exposure at $400^{\circ} \mathrm{C}$. At last, a slight shoulder can be observed at $410^{5} \mathrm{~g} \mathrm{~mol}^{-1}$ after 240 min corresponding to high degrees of conversion for the thermal degradation.

Fig. 4 shows the evolution of the weight and number average molar mass $\left(\mathrm{M}_{\mathrm{w}}\right.$ and $\left.\mathrm{M}_{\mathrm{n}}\right)$ and the polydispersity index $\left(\mathrm{I}_{\mathrm{p}}\right)$ as a function of the exposure time. As reported for PEEK by Jonas et al.

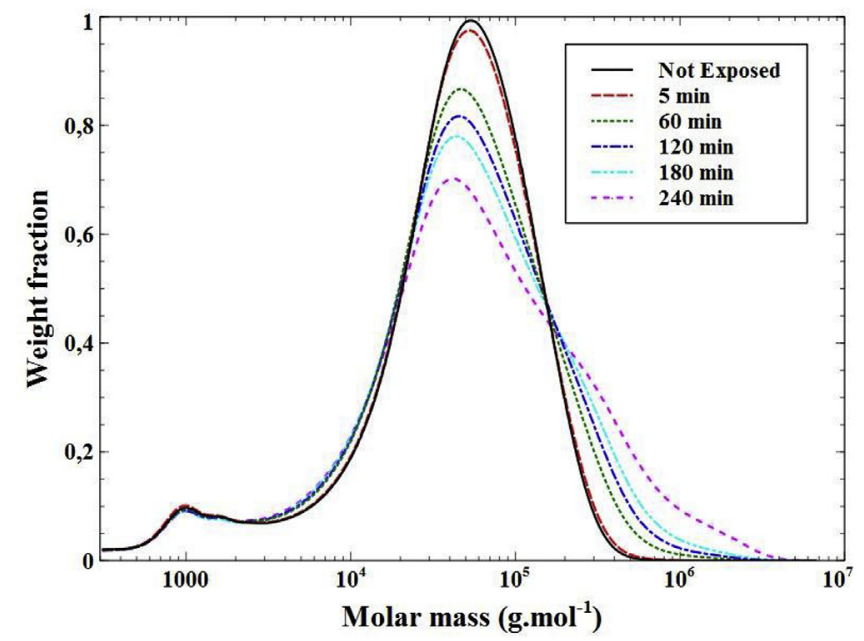

Fig. 3. Molar mass distributions (normalized weight fraction) of neat PEKK 6002 exposed at $400^{\circ} \mathrm{C}$.

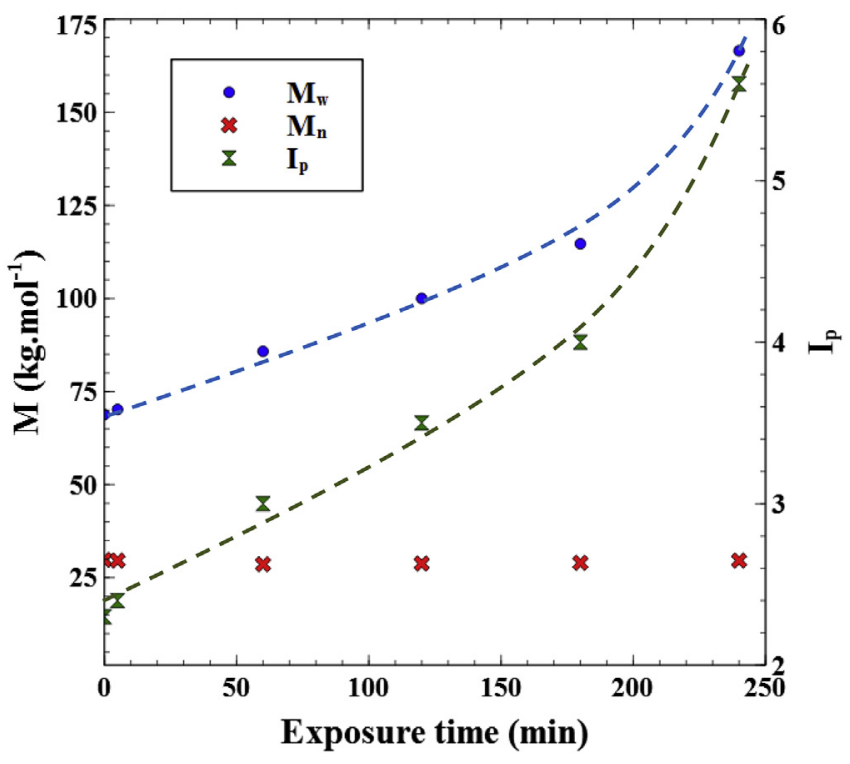

Fig. 4. Evolution of $M_{w}, M_{n}$ and $I_{p}$ as a function of the exposure time at $400{ }^{\circ} \mathrm{C}$ of neat PEKK 6002.

[6], it can be observed an increase of $\mathrm{M}_{\mathrm{w}}$ and $\mathrm{I}_{\mathrm{p}}$ with the exposure time according to the molar mass distribution changes. These increases are undoubtedly associated to a crosslink process corresponding to the reactions between thermal degradation induced radicals as shown in Fig. 1 step 4. For an exposure time of $30 \mathrm{~min}$ at $400{ }^{\circ} \mathrm{C}$ under air an increase for $\mathrm{M}_{\mathrm{w}}$ of about $7 \%$ was measured for PEEK by Jonas et al. compared to $13 \%$ for PEKK here. However, the fact that $M_{n}$ remains constant which is also the same observation than for PEEK by Jonas et al. could imply necessarily a chain scission process in a same time. The fact that the crosslinking and the chain scission processes are synchronised indicate for us that both processes have the same source in terms of radical formation. In other words, radicals coming from the chain scission mechanism (steps 1 to 3 Fig. 1) contribute the crosslinking mechanism (step 4 Fig. 1). As a result, the macromolecular changes have to take into account not only a crosslinking process but also a chain scission mechanism which is in our knowledge the first time mentioned in the literature for PAEK polymers. This point will be discussed later.

\subsection{Thermal analysis}

The impact of crosslinking on thermal properties and crystallization behavior have been studied by different authors and was shown to decrease crystallization kinetic and final crystallinity and increase glass transition $[2,6,15,16]$. In fact, crosslinking reduces the chain mobility and chain folding occurring during crystallization process. Crystallization peaks of PEKK 6002 crystallized from the melt at $230^{\circ} \mathrm{C}$ measured by DSC after different exposure times at $400{ }^{\circ} \mathrm{C}$ are presented in Fig. 5. It can be noticed that the crystallization peak decreases with the exposure time at $400^{\circ} \mathrm{C}$. As reported in a previous article [18], the integration of crystallization peak was made difficult due to the truncation of the crystallization peak beginning. Due to this truncation instead of studying the crystallization half time $t_{1 / 2}$ to assess the impact of exposure time on crystallization kinetics which could lead to strong degree of inaccuracy, the evolution of the minimum peak time $\left(t_{\text {cpeak }}\right)$ as a function of the exposure time were measured in Fig. 6. It can be observed an increase of the minimum peak time which shows that crystallization kinetics decreases with crosslinking which is consistent with the PEEK literature [6,15]. 


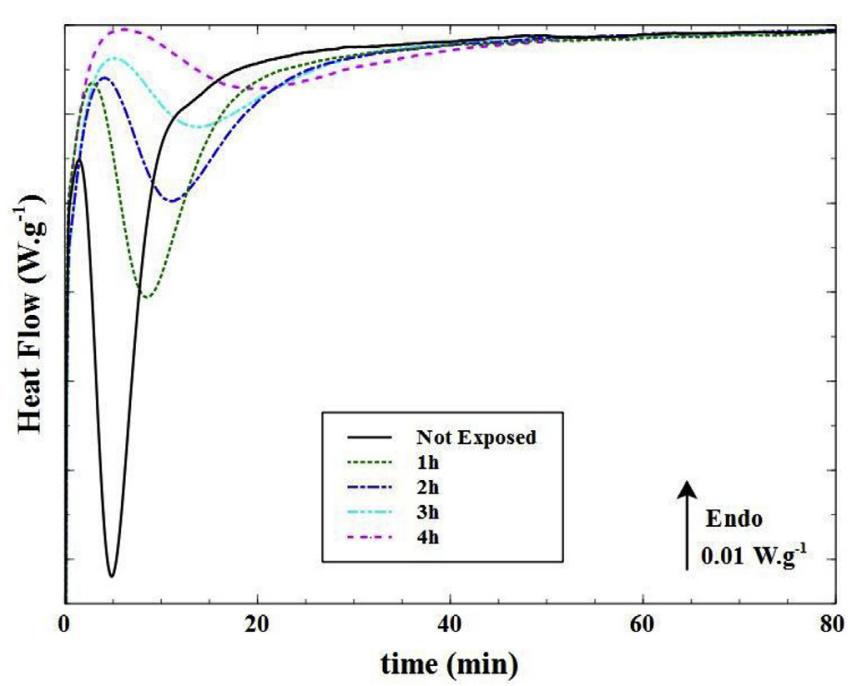

Fig. 5. Isothermal DSC thermograms of neat PEKK 6002 crystallized at $230^{\circ} \mathrm{C}$ from the melt after different exposure times at $400{ }^{\circ} \mathrm{C}$ under nitrogen.

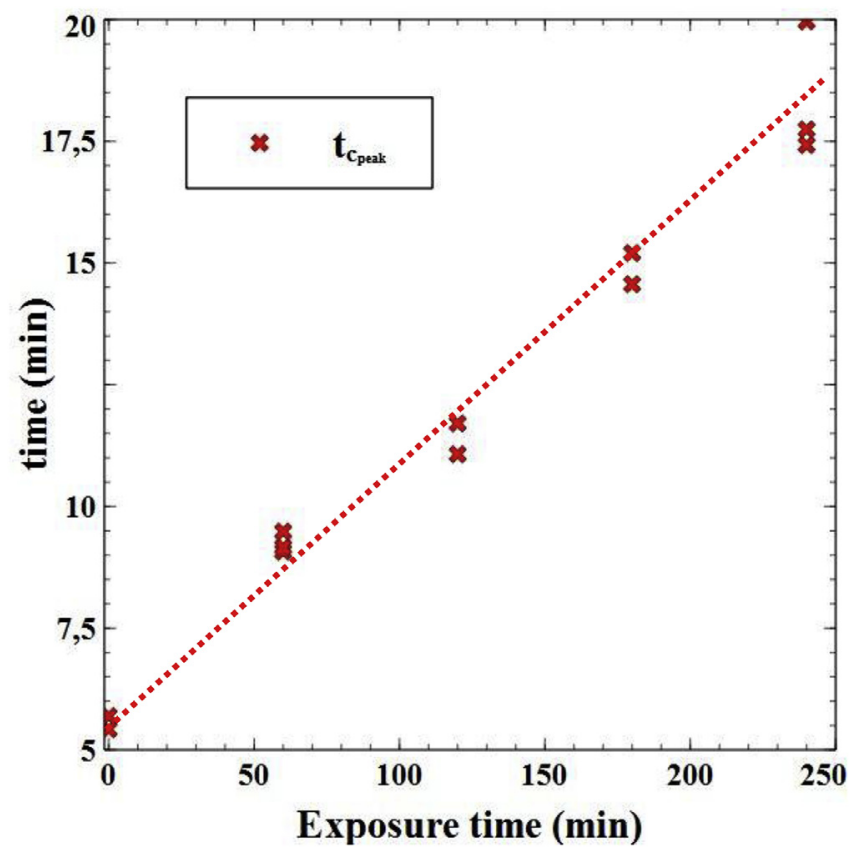

Fig. 6. Crystallization minimum peak time $t_{\text {cpeak }}$ vs exposure time at $400{ }^{\circ} \mathrm{C}$ under nitrogen of neat PEKK 6002.

The evolution of the melting enthalpy and glass transition after crystallization are presented in Fig. 7. The melting enthalpy decreases with the exposure time up to a value of about $25 \mathrm{Jg}^{-1}$ after $4 \mathrm{~h}$ exposure at $400^{\circ} \mathrm{C}$ whereas $\mathrm{T}_{\mathrm{g}}$ increases with the exposure time of about $5{ }^{\circ} \mathrm{C}$. Similar behavior was reported for PEEK $[6,15,16]$ and was attributed to crosslinking decreasing macromolecular mobility. Consequently, even if we have seen that chain scission mechanism occurs in the same time, it seems that crystallization kinetics and final crystallinity are mainly governed by the crosslinking process.

\subsection{Rheological analysis}

Isothermal rheological measurements for exposure temperatures above $T_{m}$ were carried out to investigate the evolution of

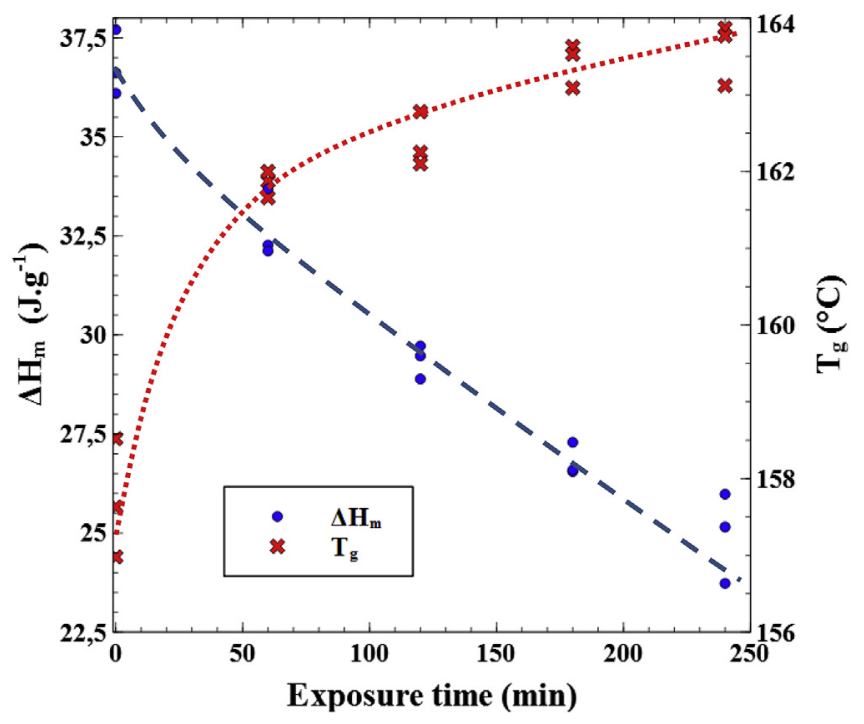

Fig. 7. Melting enthalpy $\Delta \mathrm{H}_{\mathrm{m}}$ and glass transition temperature $\mathrm{T}_{\mathrm{g}} \mathrm{vs}$ time of neat PEKK 6002 exposed at $400{ }^{\circ} \mathrm{C}$ under nitrogen during different times and crystallized at $230{ }^{\circ} \mathrm{C}$.

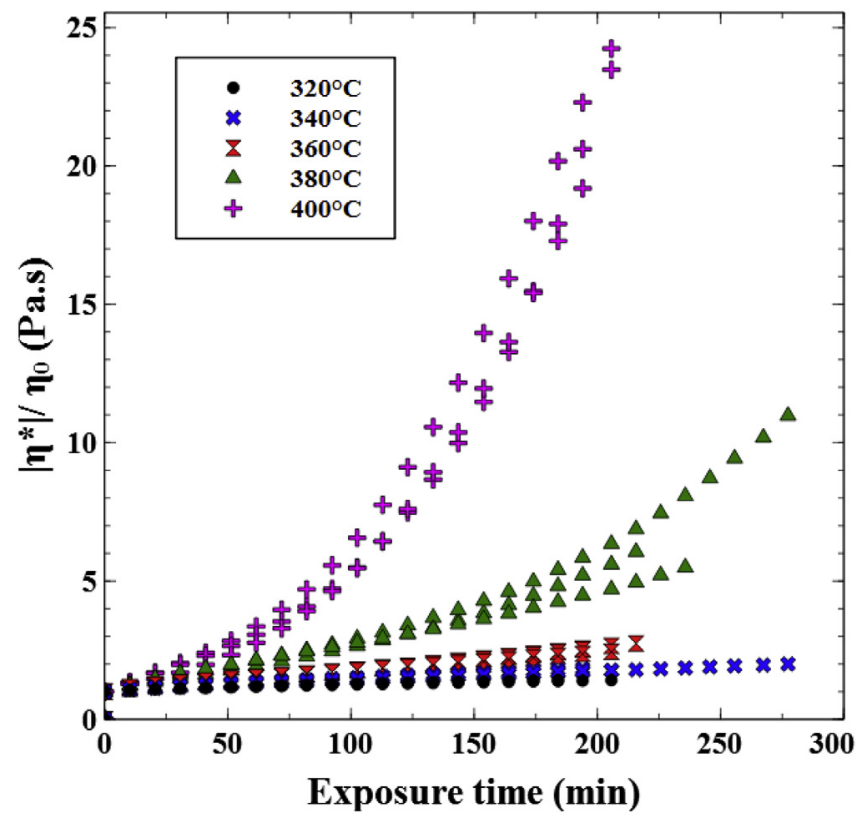

Fig. 8. Modulus of the complex viscosity divided by the Newtonian viscosity vs exposure time of neat PEKK 6002 for different isothermal tests under nitrogen.

PEKK 6002 viscosity at high processing temperatures. Fig. 8 shows the evolution of the normalized viscosity for a given temperature under nitrogen atmosphere as a function of time for different temperatures measured with a strain rate of $1 \%$ and a frequency sweep of $1 \mathrm{rad} \mathrm{s}^{-1}$. Let us recall here that the strain rate and frequency sweep values have chosen to ensure that the measured viscosity corresponds to a Newtonian viscosity. However, it is expected that the viscosity measured loses its Newtonian character at high degrees of conversion of the degradation. For exposure temperatures between $320^{\circ} \mathrm{C}$ and $360^{\circ} \mathrm{C}$, the viscosity slightly increases with the exposure time whereas above $360^{\circ} \mathrm{C}$, the viscosity strongly increases with the exposure time with an onset of $130 \mathrm{~min}$ at $380^{\circ} \mathrm{C}$ and $60 \mathrm{~min}$ at $400^{\circ} \mathrm{C}$. This phenomenon is the same as observed for PEEK in the literature $[1,9,10]$ and is consistent 
with the formation of crosslinking for PEKK heated at high exposure temperatures.

\section{Discussion}

\subsection{Crosslinking and chain scission assessment}

According to all experimental results, macromolecular architecture is strongly affected by the thermal degradation. First of all, we propose to compare the results obtained by the different ways in terms of chain scission and crosslinking number occurring during the degradation.

In a first approach, the evolution of the number of crosslinking and scission events $\mathrm{x}$ and $\mathrm{s}\left(\mathrm{mol} . \mathrm{kg}^{-1}\right)$ with the exposure time can be assessed from the number and weight average molar mass $\left(\mathrm{M}_{\mathrm{n}}\right.$ and $\mathrm{M}_{\mathrm{W}}$ ) according to the Saito's approach $[19,20]$ :

$s-x=\frac{1}{M_{n}}-\frac{1}{M_{n_{0}}}$

$\frac{s}{2}-2 x=\frac{1}{M_{w}}-\frac{1}{M_{w_{0}}}$

with $\mathrm{M}_{\mathrm{n} 0}=29.8 \mathrm{~kg} \mathrm{~mol}^{-1}$ and $\mathrm{M}_{\mathrm{w} 0}=68.8 \mathrm{~kg} \mathrm{~mol}^{-1}$. Knowing crosslink mechanism leads necessarily to branched macromolecules, the main hypothesis here is to assume that the macromolecules can be considered statistically as linear macromolecules for the degrees of conversion understudied here. This strong hypothesis is supported by the fact that less than $5 \%$ of insolubles were measured for all exposure times.

By solving the equations system (1) and (2) with GPC measurements, the evolution of $\mathrm{x}$ and $\mathrm{s}$ as a function of the exposure time at $400{ }^{\circ} \mathrm{C}$ were calculated. Results are presented in Fig. 9. It can be observed a quasi linear increase of $\mathrm{x}$ and $\mathrm{s}$ and a strong correlation between them which is consistent with the degradation mechanism scheme shown in Fig. 1. If the quasi linear behavior is a characteristic of thermal degradation (see the kinetic aspects

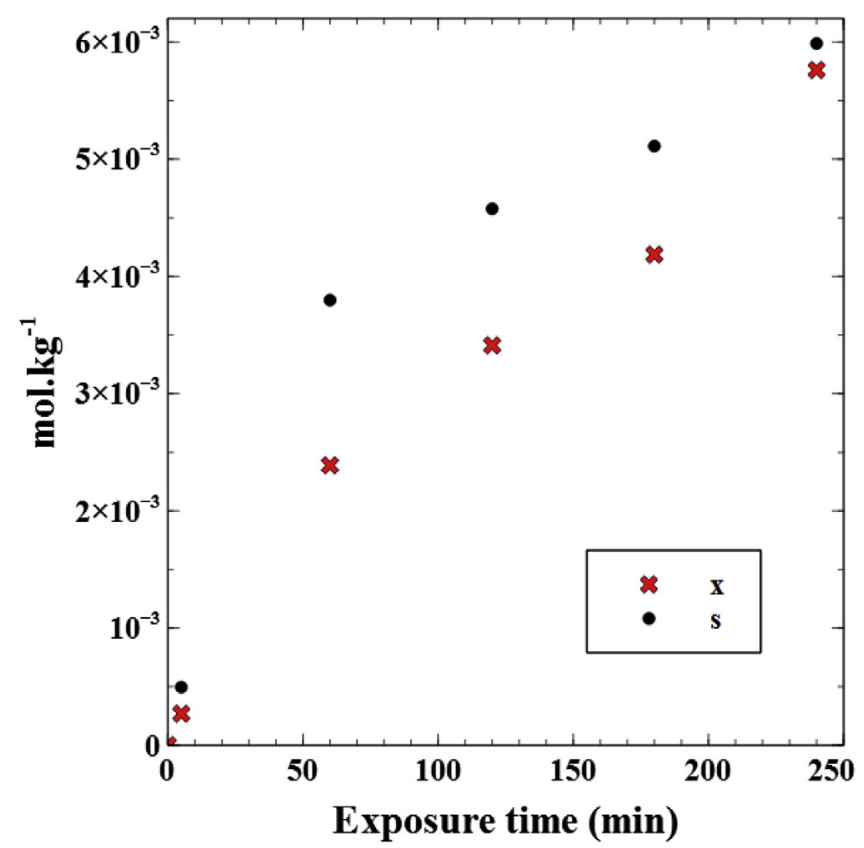

Fig. 9. Number of crosslinking and chain scission events $x$ and $s$ vs exposure time at $400{ }^{\circ} \mathrm{C}$ under air of neat PEKK 6002. below), the fact that $\mathrm{s}$ and $\mathrm{x}$ are strongly correlated comes from the constant $M_{n}$ values. Although the same experimental results were found for PEEK indicating constant $M_{n}$ and increasing of $M_{w}$ and $I_{p}$ increase by Jonas et al. [6], it is noteworthy that the Saito approach allows us to assess the appearance of chain scission in parallel to crosslinking mechanism.

The evolution of the number of crosslinking events can also be assessed from the rheological measurements. It is well known the complex viscosity measured in Fig. 8 can be related to the weight average molar mass at a temperature $\mathrm{T}$ according the following relationship:

$\left|\eta^{*}\right|=K M_{w}^{3.4}$

where $\mathrm{K}$ is a constant depending on the temperature. As it was shown from GPC measurements, the number average molar mass is quasi-constant and consequently $\mathrm{s} \approx \mathrm{x}$. With this assumption, from Eq. (2), the number of crosslinking events $x$ can be expressed by:

$x=-\frac{2}{3}\left(\frac{1}{M_{w}}-\frac{1}{M_{w_{0}}}\right)$

Consequently, from Eqs. (3) and (4), the number of crosslinking events can be expressed as a function of the modulus of the complex viscosity by:

$x=\frac{2}{3 M_{w_{0}}}\left[1-\left(\frac{\eta_{0}}{\left|\eta^{*}\right|}\right)^{\frac{1}{3.4}}\right]$

where $\mathrm{M}_{\mathrm{w} 0}=68.8 \mathrm{~kg} \mathrm{~mol}^{-1}$ and $\eta_{0}$ the viscosity Newtonian which depends on the exposure temperature. The evolution of $\mathrm{x}$ as a function of time calculated with Eq. (5) is plotted in Fig. 10. As expected, it can be observed an increase of $\mathrm{x}$ with the exposure time with highest values at $400^{\circ} \mathrm{C}$. We can witness that the crosslinking process doesn't exhibit a significant induction period: the crosslinking rate is maximum at the beginning of the exposure which is characteristic of thermal degradation where the initiation step controls the kinetic (see kinetic part $\S 4.2$ ).

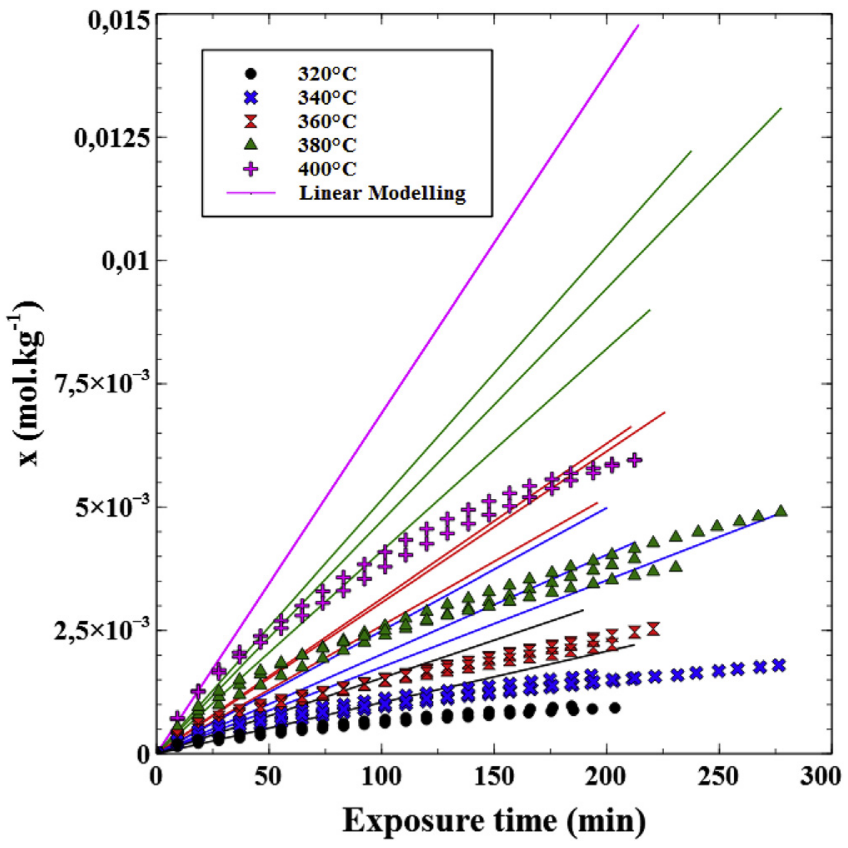

Fig. 10. Number of crosslinking events $x$ vs exposure time of neat PEKK 6002 for different temperatures under nitrogen with the linear modelling. 
Fig. 11 shows the comparison of the values of the number of crosslinking events $\mathrm{x}$ of PEKK 6002 exposed at $400{ }^{\circ} \mathrm{C}$ determined by rheological (viscosity) and GPC $\left(M_{n}, M_{W}\right)$ measurements. Interestingly, a good correlation between both methods is put in evidence especially at low degrees of conversion. At high degree of conversion, the values of $\mathrm{x}$ assessed by GPC appear to be slightly lower than for those assessed by the rheological measurements for values higher than $310^{-3} \mathrm{~mol} \mathrm{~kg}^{-1}$ in our case. This discrepancy can be attributed logically to the overestimation of the crosslink number by the rheological measurements or by its underestimation by GPC measurements. On the one hand, the overestimation from a rheological data can be associated to the polydispersity increase associated to the polymer branching. Indeed, for a given molar mass, a branched polymer shows a higher viscosity compare to a linear one. In other words, the scaling law in Eq. (5) has to be modified. On the other hand, some crosslinks can be trapped in the insoluble fraction leading to reduce artificially the $\mathrm{M}_{\mathrm{W}}$ increase measured by GPC during the degradation. As a result, the observed correlation shows that the proposed assessment of $\mathrm{x}$ and $\mathrm{s}$ is valid at low degrees of conversion although this first approach includes some strong hypotheses.

The last way to asses $x$ and $s$ in the literature [21] is to follow the evolution of the number crosslinking events $\mathrm{x}$ with the glass transition temperature $T_{g}$ thanks to the Fox Flory law [22]:

$T_{g}=T_{g_{\infty}}-\frac{k_{F F}}{M_{n}}$

where $T_{g_{\infty}}$ is the theoretical glass transition of a linear polymer with an infinite molar mass and $\mathrm{k}_{\mathrm{FF}}=203.6 \mathrm{~K} \mathrm{~kg} \mathrm{~mol}^{-1}$ is the constant of Fox Flory determined for PEEK. The difference of $T_{g}$ before and after exposure can be expressed by:

$T_{g}-T_{g_{0}}=-k_{F F}\left(\frac{1}{M_{n}}-\frac{1}{M_{n_{0}}}\right)$

where $\mathrm{T}_{\mathrm{g} 0}$ is the glass transition at the initial time. From Eq. (1), Eq. (7) can thus be written:

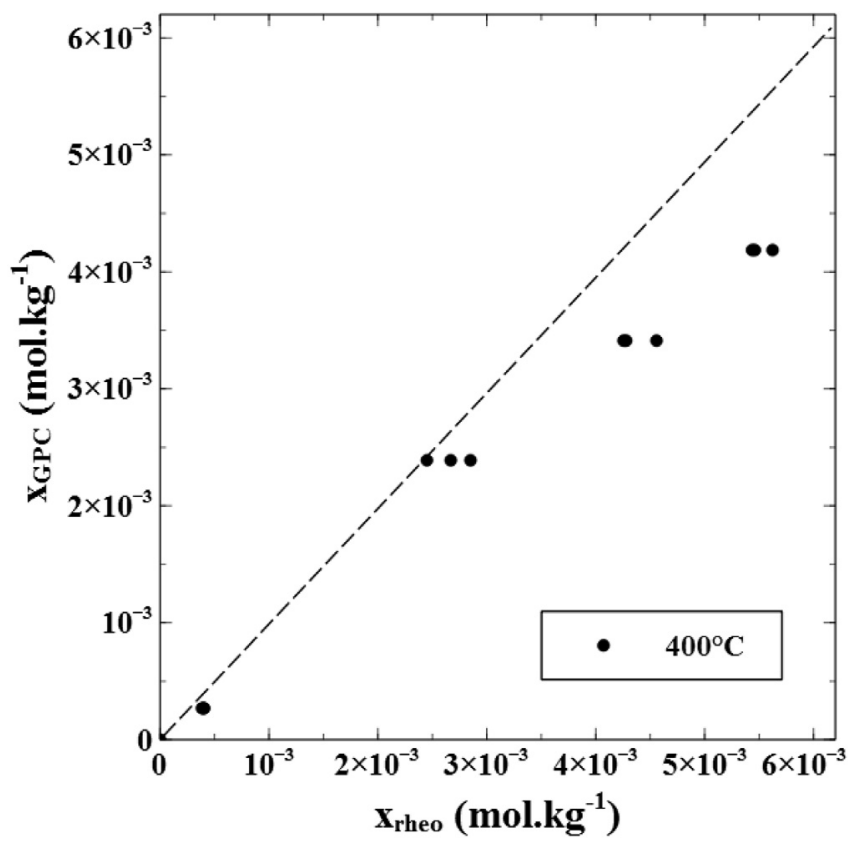

Fig. 11. Comparison of the number of crosslinking events $x$ of PEKK 6002 exposed at $400{ }^{\circ} \mathrm{C}$ determined by rheological measurements and GPC measurements.
$T_{g}-T_{g_{0}}=-k_{F F}(s-x)$

However, according to our GPC measurements where $M_{n}$ remains constant, the $\mathrm{T}_{\mathrm{g}}$ predicted by Eq. (8) should be constant which is not consistent regarding Fig. 7. Thus, in our case the Fox Flory law cannot be used to assess the evolution of the number crosslinking events. The main cause could be explained by the fact that the Fox Flory law was established for monodisperse polymers such as PS. As a result, the use of the $T_{g}$ changes during degradation to monitor macromolecular modification is highly questionable.

\subsection{Crosslinking kinetic modelling}

Attempts were made to model the evolution of the number of crosslinking events as a function of the thermal processing temperature. A mechanistic approach can be carried out to model $\mathrm{x}$ depending on the temperature for any exposure time by exploiting the chemical reaction equations leading to crosslinking. As presented previously, the different steps of the crosslinking mechanism under nitrogen atmosphere can be expressed by:

$P H \rightarrow P^{\circ}+P^{\circ}\left(\mathrm{k}_{0}\right)$

$P^{\circ}+P H \rightarrow P H+P^{\circ}\left(\mathrm{k}_{3}\right)$

$P^{\circ}+P^{\circ} \rightarrow x\left(\mathrm{k}_{4}\right)$

where $\mathrm{PH}$ corresponds to the macromolecular chains, $\mathrm{P}^{\circ}$ to phenyl radicals, $x$ to the number of crosslinking events $\left(\mathrm{mol} \mathrm{kg}^{-1}\right)$ and $\mathrm{k}_{0}$, $\mathrm{k}_{3}$ and $\mathrm{k}_{4}$ to the reaction rate constants of the initiation, propagation and termination by crosslinking steps respectively. The kinetic scheme of crosslinking mechanism can thus be written:

$\frac{d\left[P^{\circ}\right]}{d t}=2 k_{0}[P H]-2 k_{4}\left[P^{\circ}\right]^{2}$

$\frac{d[P H]}{d t}=-k_{0}[P H]$

$\frac{d x}{d t}=\gamma_{4} k_{4}\left[P^{\circ}\right]^{2}$

where $\left[\mathrm{P}^{\circ}\right],[\mathrm{PH}]$ correspond to the concentration of PEKK monomer and macromolecular chains respectively, $\mathrm{k}_{0}, \mathrm{k}_{3}$ and $\mathrm{k}_{4}$ to the reaction constants and $\gamma_{4}$ is a constant which is between 0 and 1 allowing to take into account the fact that radicals can also rearrange by internal combination.

In first approach, it can be assumed that at low degree of conversion the PH consumption is negligible. Hence, Eq. (12) becomes:

$\frac{d\left[P^{\circ}\right]}{d t}=2 k_{0}[P H]_{0}-2 k_{4}\left[P^{\circ}\right]^{2}$

With $[\mathrm{PH}]_{0}$ the initial concentration of $\mathrm{PH}$ which depends on the number of potentially sites which can be activated for crosslinking reactions so precisely the sites where macromolecular chains can be broken:

$[P H]_{0}=n_{\text {sits }} \frac{1}{M_{0_{\text {PEKK }}}} d_{\text {PEKK }}$

Where $\mathrm{n}_{\text {sits }}$ is the number of sits which can be activated, $M_{\text {OPEKK }}=300.3 \mathrm{~g} \mathrm{~mol}^{-1}$ is the molar mass and $d_{\text {PEKK }}=1.3$ is the density. $\mathrm{n}_{\text {sits }}$ can take three different values, if chains scissions occurs at the carbonyl functional groups $n_{\text {sits }}=4$, if chains scissions 
occurs at the ether bonds $n_{\text {sits }}=2$ and finally if we consider that the chain scission occurs randomly at the carbonyle and ether bonds $\mathrm{n}_{\text {sits }}=6$.

By solving Eq. (15), the concentration of alkyls radicals $\mathrm{P}^{\circ}$ can be expressed by:

$\left[P^{\circ}\right]=\left[P^{\circ}\right]_{\text {stat }} \frac{1-\exp \left(-\frac{t}{\tau}\right)}{1+\exp \left(-\frac{t}{\tau}\right)}$

With $\left[P^{\circ}\right]_{\text {stat }}$ the concentration of alkyl radicals at the stationary state equal to:

$\left[P^{\circ}\right]_{\text {stat }}=\left(\frac{k_{0}[P H]_{0}}{k_{4}}\right)^{1 / 2}$

And the characteristic time to reach the stationary state $\tau$ equal to:

$\tau=\frac{1}{4\left(k_{0} k_{4}[P H]_{0}\right)^{1 / 2}}$

As alkyle radicals $\left(\mathrm{P}^{\circ}\right)$ are highly reactive $\left(\mathrm{k}_{4}>10^{7} \mathrm{~mol} \mathrm{l}^{-1} \mathrm{~s}^{-1}\right)$, the stationary state for $\mathrm{P}^{\circ}$ is reached at the very beginning of exposure. Thus, at low degree of conversion, it can be written:

$\left[P^{\circ}\right]=\left(\frac{k_{0}[P H]_{0}}{k_{4}}\right)^{1 / 2}$

Consequently, for low exposure time, by solving Eq. (14), the number of crosslinking events $\mathrm{x}$ is equal to:

$x=\gamma_{4} k_{0}[P H]_{0} t$

This equation corresponds to a linear equation which passes by 0 with a slope of $\gamma_{4} k_{0}[\mathrm{PH}]_{0}$ corresponding to the apparent crosslinking kinetics $\mathrm{k}_{\mathrm{app}}$. Consequently, straight lines were fitted with the beginning of the number of crosslinking events $\mathrm{x}$ curves plotted in Fig. $10(t<20 \mathrm{~min})$ to determine $\mathrm{k}_{\mathrm{app}}$ depending on the exposure temperature.

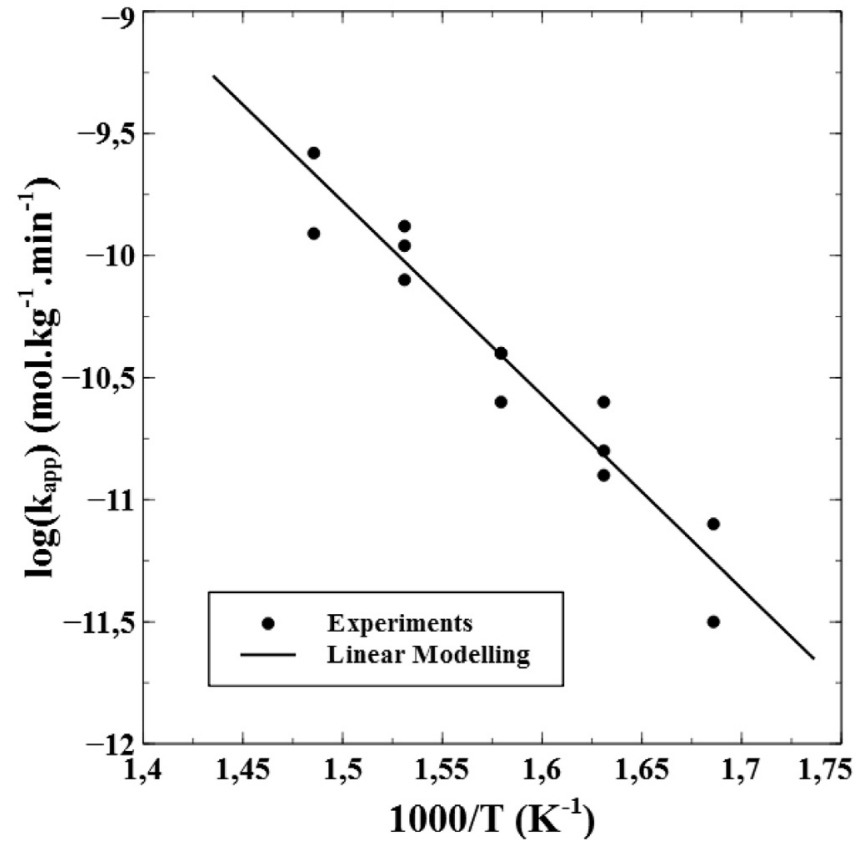

Fig. 12. Arrhenius plot of the apparent crosslinking kinetics of neat PEKK 6002 under nitrogen.
The logarithm of the apparent crosslinking kinetics $k_{a p p}$ is plotted as a function of the inverse of the exposure temperature in Fig. 12. First, it can be observed $\mathrm{k}_{\mathrm{app}}$ follows an Arrhenius behavior. The apparent crosslinking activation energy $E_{a k a p p}$ and $k_{a p p 0}$ have been determined to be equal to $65.9 \mathrm{~kJ} \mathrm{~mol}^{-1}$ and $8.27 \mathrm{~mol} . \mathrm{kg}^{-1} \mathrm{~min}^{-1}$. It's noteworthy that the crosslinking activation energy of PEKK is quite lower than the value reported from mass loss measurements (TGA) in the literature for carbon PEKK close to $210 \mathrm{~kJ} \mathrm{~mol}^{-1}$ [13] and for PEEK between 220 and $320 \mathrm{~kJ} \mathrm{~mol}^{-1}$ over temperatures ranging from 400 to $700{ }^{\circ} \mathrm{C}[3,23,24]$.

\section{Conclusion}

From rheological, GPC and DSC measurements, it has been shown that PEKK 6002 matrix is modified above $320^{\circ} \mathrm{C}$ under nitrogen or lack of oxygen. The witnessed modifications are characterized by an increase of the viscosity, the weight average molar mass $M_{w}$ and the glass transition temperature $T_{g}$. If all these phenomena are typical to a crosslinking/branching mechanisms occurring during exposure, the fact that $\mathrm{M}_{\mathrm{n}}$ values remain constant indicates that a chain scission mechanism occurs in the same time. According to Saito's approach based on molar masses changes, it has been established that for each crosslinking event, one chain scission occurs. Based on this result and the viscosity changes as a function of the exposure temperatures, the crosslinking kinetics has been investigated. These mechanisms have been observed to be thermally activated and following an Arrhenius law. From the kinetic scheme of crosslinking mechanism, crosslinking/branching kinetics has been modelled with a linear model for low exposure times $(t<20 \mathrm{~min})$. Finally, crosslinking occurring at the melting state has been found to decrease crystallinity and crystallization kinetics with the decrease of the crystallization melting enthalpy and the increase of the minimum crystallization peak time.

\section{Acknowledgments}

The authors wish to thank Arkema Company for providing PEKK materials and having carried out Gel Permeation Chromatography (GPC) measurements. ANRT (CIFRE $\mathrm{N}^{\circ} 2014 / 0797$ ) is gratefully acknowledged for financial support.

\section{References}

[1] C.-M. Chan, S. Venkatraman, Crosslinking of poly(arylene ether ketone)s 1. Rheological behavior of the melt and mechanical properties of cured resin, J. Appl. Polym. Sci. 32 (1986) 5933-5943, https://doi.org/10.1002/ app.1986.070320722.

[2] C.-M. Chan, S. Venkatraman, Crosslinking of poly(arylene ether ketones). II. Crystallization kinetics, J. Polym. Sci. Part B Polym. Phys. 25 (1987) 1655-1665, https://doi.org/10.1002/polb.1987.090250808.

[3] J.N. Hay, D.J. Kemmish, Thermal decomposition of poly(aryl ether ketones), Polymer 28(1987)2047-2051, https://doi.org/10.1016/0032-3861(87)90039-5.

[4] M. Day, D. Sally, D.M. Wiles, Thermal degradation of poly(aryl-ether-etherketone): experimental evaluation of crosslinking reactions, J. Appl. Polym. Sci. 40 (1990) 1615-1625, https://doi.org/10.1002/app.1990.070400917.

[5] M. Day, J.D. Cooney, D.M. Wiles, The thermal degradation of poly(aryl-ether-ether-ketone) (PEEK) as monitored by pyrolysis-GC/MS and TG/MS, J. Anal. Appl. Pyrolysis 18 (1990) 163-173, https://doi.org/10.1016/ 0165-2370(90)80005-9.

[6] A. Jonas, R. Legras, Thermal stability and crystallization of poly(aryl ether ether ketone), Polymer 32 (1991) 2691-2706, https://doi.org/10.1016/00323861(91)90095-Z.

[7] C. Nicodeau, Continuous Welding Modeling of Thermoplastic Matrix Composites, phd thesis, Arts Métiers ParisTech, 2005, https://pastel.archivesouvertes.fr/pastel-00001506/document. (Accessed 26 January 2015).

[8] P. Patel, T.R. Hull, R.W. McCabe, D. Flath, J. Grasmeder, M. Percy, Mechanism of thermal decomposition of poly(ether ether ketone) (PEEK) from a review of decomposition studies, Polym. Degrad. Stabil. 95 (2010) 709-718, https:// doi.org/10.1016/j.polymdegradstab.2010.01.024.

[9] K.L. White, L. Jin, N. Ferrer, M. Wong, T. Bremner, H.-J. Sue, Rheological and thermal behaviors of commercial poly(aryletherketone)s, Polym. Eng. Sci. 53 
(2013) 651-661, https://doi.org/10.1002/pen.23309.

[10] V. Mylläri, T.-P. Ruoko, J. Vuorinen, H. Lemmetyinen, Characterization of thermally aged polyetheretherketone fibres - mechanical, thermal, rheological and chemical property changes, Polym. Degrad. Stabil. 120 (2015) 419-426, https://doi.org/10.1016/j.polymdegradstab.2015.08.003.

[11] E. Courvoisier, Y. Bicaba, X. Colin, Multi-scale and multi-technique analysis of the thermal degradation of poly(ether ether ketone), Polym. Degrad. Stabil. 151 (2018) 65-79.

[12] G. Dolo, J. Férec, D. Cartié, Y. Grohens, G. Ausias, Model for thermal degradation of carbon fiber filled poly(ether ether ketone), Polym. Degrad. Stabil. 143 (2017) 20-25, https://doi.org/10.1016/j.polymdegradstab.2017.06.006.

[13] P. Tadini, N. Grange, K. Chetehouna, N. Gascoin, S. Senave, I. Reynaud, Thermal degradation analysis of innovative PEKK-based carbon composites for hightemperature aeronautical components, Aero. Sci. Technol. 65 (2017) 106-116, https://doi.org/10.1016/j.ast.2017.02.011.

[14] C.J. Tsai, L.H. Perng, Y.C. Ling, A study of thermal degradation of poly(arylether-ether-ketone) using stepwise pyrolysis/gas chromatography/mass spectrometry, Rapid Commun. Mass Spectrom. 11 (1997) 1987-1995, https:// doi.org/10.1002/(SICI)1097-0231(199712)11:18<1987::AIDRCM100>3.0.CO;2-Q.

[15] Y. Deslandes, M. Day, N.-F. Sabir, T. Suprunchuk, Crystallization of poly(arylether-ether-ketone): effect of thermal history of the melt on crystallization kinetics, Polym. Compos. 10 (1989) 360-366, https://doi.org/10.1002/ pc.750100513.

[16] M. Day, T. Suprunchuk, J.D. Cooney, D.M. Wiles, Thermal degradation of poly(aryl-ether-ether-ketone) (PEEK): a differential scanning calorimetry study, J. Appl. Polym. Sci. 36 (1988) 1097-1106, https://doi.org/10.1002/ app.1988.070360510.

[17] K.H. Gardner, B.S. Hsiao, R.R. Matheson, B.A. Wood, Structure, crystallization and morphology of poly (aryl ether ketone ketone), Polymer 33 (1992) 2483-2495, https://doi.org/10.1016/0032-3861(92)91128-O.

[18] T. Choupin, B. Fayolle, G. Régnier, C. Paris, J. Cinquin, B. Brulé, Isothermal crystallization kinetic modeling of poly(etherketoneketone) (PEKK) copolymer, Polymer 111 (2017) 73-82, https://doi.org/10.1016/ j.polymer.2017.01.033.

[19] O. Saito, Effects of high energy radiation on polymers II. End-linking and gel fraction, J. Phys. Soc. Jpn. 13 (1958) 1451-1464, https://doi.org/10.1143/ JPSJ.13.1451.

[20] B. Fayolle, X. Colin, L. Audouin, J. Verdu, Mechanism of degradation induced embrittlement in polyethylene, Polym. Degrad. Stabil. 92 (2007) 231-238, https://doi.org/10.1016/j.polymdegradstab.2006.11.012.

[21] E. Richaud, P. Ferreira, L. Audouin, X. Colin, J. Verdu, C. Monchy-Leroy, Radiochemical ageing of poly(ether ether ketone), Eur. Polym. J. 46 (2010) 731-743, https://doi.org/10.1016/j.eurpolymj.2009.12.026.

[22] T.G. Fox, P.J. Flory, Second order transition temperatures and related properties of polystyrene. I. Influence of molecular weight, J. Appl. Phys. 21 (1950) 581-591, https://doi.org/10.1063/1.1699711.

[23] M. Day, J.D. Cooney, D.M. Wiles, A kinetic study of the thermal decomposition of poly(aryl-ether-ether-ketone) (PEEK) in nitrogen, Polym. Eng. Sci. 29 (1989) 19-22, https://doi.org/10.1002/pen.760290105.

[24] J.-D. Nam, J.C. Seferis, Generalized composite degradation kinetics for polymeric systems under isothermal and nonisothermal conditions, J. Polym. Sci. Part B Polym. Phys. 30 (1992) 455-463, https://doi.org/10.1002/ polb.1992.090300505. 